\title{
AN ANALYSIS OF EXPERTS' RATINGS OF ERGONOMIC STRESS
}

\author{
W. Monroe Keyserling and Stephen J. Wittig \\ Center For Ergonomics, Department of Industrial and Operations Engineering, The University of Michigan, \\ 1205 Beal Avenue, Ann Arbor, Ml 48109-2117 (U.S.A.)
}

(Received August 25, 1987; accepted in revised form November 3. 1987)

\begin{abstract}
Experts in the field of industrial ergonomics are frequently called upon to visit workplaces in order to evaluate and rate ergonomic stressors which may cause fatigue, discomfort, or injury. The objective of this study was to evaluate the extent of agreement among experts' perceptions of four categories of ergonomic stress: materials handling (e.g., lifting), upper extremity activities, posture, and energy expenditure.

A panel of five experts observed ten jobs in manufacturing and warehouse facilities. A threepoint scale $(1=$ insignificant stress, $2=$ moderate stress, $3=$ high stress) was used to rate the jobs in each of the four stress categories. In addition, lifting stresses on each job were analyzed using methods
\end{abstract}

described in the NIOSH Work Practices Guide for Manual Lifting. The resulting data were analyzed to determine the level of expert consensus and the level of agreement with the NIOSH results.

In general, there was a high level of consensus among the experts. Perfect agreement (identical ratings by all five experts) was obtained for 30 percent of the experts' scores; while consensus agreement (identical ratings by three or more experts) was obtained for 87.5 percent of the scores. In general, the experts' perceptions agreed with the NIOSH ratings of lifting stress. On a few jobs, however, the expert panel considered lifting stresses to be greater than predicted by the NIOSH ratings.

\section{INTRODUCTION}

Jobs which expose workers to excessive ergonomic stresses can cause a variety of occupational health problems including fatigue, discomfort, and disability. These stresses may result from awkward posture, excessive force demands, highly repetitive actions and/or excessive energy expenditure.

Acute and chronic musculoskeletal disorders have been well documented in industry. Kelsey et al. (1978) summarized several health surveys and found that:
- About 20 million people in the United States have musculoskeletal impairments.

- At least 85,000 workers in the United States receive permanent disability ratings each year for musculoskeletal problems (primarily low back pain and upper extremity cumulative trauma disorders).

- Back pain accounts for one-sixth of all workplace injuries and is the most frequent cause of activity limitations in workers under 45 years of age in the United States.

- In the United States, musculoskeletal disorders 
are ranked near the top of conditions requiring medical treatment: Specifically, musculoskeletal disorders are ranked:

- Second among reasons for seeing a physician,

- Third among disorders requiring hospital surgery, and

- Fifth among reasons for visiting hospitals.

Furthermore, eight out of ten adults experience back pain during their working careers, resulting in significant medical and compensation costs (Snook, 1978).

Although excessive energy expenditure due to work requirements has not been strongly linked to occupational disease, metabolically strenuous work can result in either whole body or localized fatigue. Chaffin (1972) found that jobs requiring repeated moderate or heavy whole body exertions can lead to discomfort, loss of coordination, loss of strength, and strain on the cardiovascular system. Jobs requiring sustained postures or repeated use of specific muscle groups can lead to a general loss of coordination, localized muscle discomfort, and cardiovascular strain (Armstrong et al., 1980).

Individuals with expertise in occupational ergonomics are frequently required to identify jobs which are likely to cause the above problems and to provide advice on approaches to eliminate ergonomic stressors. Frequently, the expert is requested to assess numerous jobs during a plant "walk-through". Due to time and cost restraints, the expert may be restricted to $10-15$ minutes to evaluate each job. This does not leave the expert enough time to use detailed quantitative methods, such as biomechanical models (Chaffin and Andersson, 1984) and/or calorimetry (Astrand and Rodahl, 1986), as a basis for hazard evaluation. Thus, the expert is limited to using on-site observations, information provided by the operator, supervisor, and/or engineers, plus his/her own experience when formulating an opinion or rating of the hazard.

The skills used by ergonomic experts to formulate an opinion are the result of concentrated training and research in the laboratory and in the field. Typical areas of emphasis include engineering psychology, biomechanics, industrial engineering, medicine, epidemiology, and work physiology. Due to the complexity of each area, experts tend to specialize in one or two areas. When called upon to perform a walk-through, however, the expert is expected to be sufficiently knowledgeable in all aspects of ergonomics to render an accurate assessment of each job.

A review of recent literature failed to identify previous research which addresses the accuracy of expert ratings or the degree of expert consensus in the assessment of ergonomic risks. Expert analysis has been used, however, in other fields to establish probability distributions for catastrophic events, such as nuclear power plant accidents (Hofer et al., 1985). Procedures have also been developed to improve the ability to elicit information from experts and to improve the extent of expert consensus. A well-known method is the Delphi technique developed by the Rand Corporation in 1948. This technique consists of a set of procedures to canvass, integrate, and improve experts' judgments through feedback. Each expert on a panel anonymously replies to the problem(s) by responding to a questionnaire. The questionnaires are then collected, analyzed, and returned to each expert with a summary of how the full panel responded. Each expert may then change his/her response, based on the replies of the other experts, if so desired. This process is iterated until the group reaches a consensus or until group members no longer wish to revise their individual responses (Apostolakis and Mosleh, 1979; Linstone and Turhoff, 1975).

Due to the absence of literature discussing the ability of experts to assess ergonomic stresses, a pilot study was performed. The purpose of this study was to determine how well experts in the field of industrial ergonomics agreed on the nature and magnitude of hazards on industrial jobs. A secondary objective was to determine identifiable causes of disagreement, such as differences in an expert's background or specialization. A final objective was to determine how well the experts' ratings agreed with objective measures of ergonomic strain.

\section{METHODS}

\section{Procedures}

A panel of five university researchers with expertise in occupational ergonomics was assembled 
to participate in this investigation. (See Appendix A for descriptions of panel members.) During a preliminary meeting, the panel was briefed on the objectives of the study and trained to use a simple, ordinal scoring system (described below) for rating ergonomic stresses on industrial jobs. After this meeting, the panel visited two warehouse facilities and one manufacturing facility to assess ergonomic stresses on ten different repetitive, short-cycle jobs. (See Appendix B for a brief description of each job.) While performing these assessments, the experts were not permitted to discuss their perceptions of ergonomic stresses with other panel members. This restriction was imposed to assure the independence of the ratings developed by each expert.

One of the experts visited the study jobs on a second occasion to re-rate the jobs. The time between site visits was 11 days and the expert did not review notes between visits.

\section{Ergonomic stresses of interest}

The experts observed several cycles of each study job during a walk-through visit at the cooperating facilities. During the observation period (typically 10-30 minutes per job), representatives of management and labor answered the experts' questions concerning job requirements, such as the weight of parts lifted, production rates, and work/rest schedules. Experts' perceptions of the following four categories of ergonomic stress were recorded at the end of the observation period:

\section{Manual materials handling (MMH) activities}

This category included stresses associated with strength-demanding materials handling tasks (e.g., lifting, carrying, pushing, pulling, etc.) which could lead to overexertion injuries of the back and other body regions (NIOSH, 1981; Chaffin and Andersson, 1984). Analysts were instructed to focus their attention on the magnitude of the forces exerted and the body geometry maintained during materials handling tasks in order to estimate the likelihood of overexertion musculoskeletal injuries.

\section{Upper Extremity (UE) activities}

This category included stresses associated with actions of the hands, arms, and shoulders that could lead to cumulative trauma disorders, such as tendinitis, synovitis, and carpal tunnel syndrome (Silverstein, 1985; Armstrong, 1986). Analysts were instructed to focus their attention on the frequency, force, and posture associated with hand-intensive tasks. Other factors, such as exposure to vibration and localized mechanical stresses were also considered when estimating the likelihood of an upper extremity injury.

\section{Posture}

This category included non-neutral postures of the trunk, neck, and/or shoulders that could lead to localized muscle fatigue and/or musculoskeletal disorders (Hagberg, 1982; Punnett et al, 1987). Analysts were instructed to focus their attention on the trunk (flexion, lateral bending, or twisting), the neck (flexion, extension, twisting, or lateral bending), and the shoulder (flexion or abduction). Temporal aspects, such as frequency and duration of these non-neutral postures, were also considered by the analysts in order to estimate the potential for injury.

\section{Metabolic energy expenditure and whole body fatigue}

This category included work activities requiring high levels of energy expenditure which could lead to excessive loading of the cardiovascular system and whole body fatigue, such as climbing or repetitive/prolonged lifting of heavy loads (Durnin and Passmore, 1976; NIOSH, 1981). Analysts were also instructed to consider environmental effects (e.g., heat stress) when estimating the potential for job-induced whole body fatigue.

\section{The scoring system}

An ordinal scoring system was developed to record the experts' perceptions of ergonomic stresses. This system required that the experts independently consider the materials handling, upper extremity, posture, and energy expenditure stresses on each job. The perceived hazard level in each category was then recorded using the following three-level rating scheme:

Insignificant. Jobs given this rating were judged to be free of potentially harmful ergonomic stresses in the category of interest. The expert believed that the job was sufficiently safe that no 
follow-up action (i.e., additional analyses and/or job modifications) would be required or necessary.

Moderate. Jobs given this rating were judged to present moderate ergonomic stresses in the category of interest. The expert believed that follow-up analyses using quantitative methods (e.g. NIOSH Work Practices Guide to assess manual lifting, indirect calorimetry to assess energy expenditure, posture measurement techniques, etc.) were justified to confirm perceptions and to determine the necessity for design and/or work methods changes.

High. Jobs given this rating were judged to present major ergonomic stresses in the category of interest. This rating indicated that the expert believed the probability of injury was sufficiently high to justify immediate, detailed follow-up analyses. Furthermore, the expert believed that high priority should be given to redesigning the job in order to eliminate or reduce the level of ergonomic stress.

\section{Objective measures of ergonomic stress}

A secondary purpose of this experiment was to compare the experts' ratings to a generallyaccepted, objective measure of ergonomic stress. To perform this comparison, it was necessary that the objective measurement system generate scores that could be easily compared to the experts' ratings (i.e., a three-level ordinal scoring system with categories similar to those defined above). Such a comparison was feasible for the manual materials handling category due to the existence of the NIOSH Work Practices Guide for Manual Lifting (NIOSH, 1981).

The NIOSH WPG uses direct measurements of job requirements (e.g., object weight, workplace and task geometry, and lifting frequency) to assign lifting tasks to one of three categories:

Acceptable. Lifting stresses are sufficiently low that most members of the working population can perform the job with only nominal risk of injury.

Administrative controls required. Lifting stresses are sufficiently high that some members of the workforce are at increased risk of injury; measures should be taken to protect these individuals.

Hazardous. Lifting stresses are so high that most members of the workforce are at substantial risk of injury; the job should be redesigned to reduce or eliminate the lifting stresses.

Although the definitions of the three NIOSH categories were not identical to the "insignificant", "moderate", and "high" categories used in this study, the two systems were sufficiently similar to perform comparisons.

Comparisons could not be performed for the "upper extremity", "posture", and "metabolic" categories due to the lack of generally-accepted, three-level ordinal scoring systems for rating these stresses.

\section{Data reduction and analysis}

To simplify data recording and analysis, the experts were instructed to use the following numeric scores when documenting their ratings:

1-Insignificant stress.

2-Moderate stress.

3 - High stress.

A total of 20 observations (5 experts $\times 4$ rating categories) were obtained for each job.

A major objective of this investigation was to ascertain the extent of agreement among the experts' ratings of ergonomic stress. To do this, the following numeric scoring scheme was developed to describe the level of consensus for a given stress category on a given job:

5-Perfect agreement (all five experts recorded identical ratings).

4-Strong agreement (four experts recorded identical ratings).

3-Consensus (three experts recorded identical ratings).

2-Poor agreement (two adjacent modes of expert agreement).

1 - Very poor agreement (two modes, one at the "insignificant" stress level, one at the "high" stress level).

This scoring scheme was used to describe expert consensus on 40 items ( 4 categories of ergonomic stress $\times 10$ jobs).

Data analyses were performed using an Apple 
Macintosh Plus personal computer and the "Stat View $512+"$ (Abascus Concepts, 1986) statistical software package. Using the numeric scoring systems described above, simple descriptive statistics (mean, mode, standard deviation, etc.) were computed for the experts' perceptions and for expert consensus. These statistics were determined for each category of ergonomic stress for the ten study jobs.
Because ordinal rating methods were used to describe expert perceptions and expert consensus, parametric statistical procedures (e.g., analysis of variance) could not be used for hypothesis testing. Instead, it was necessary to use non-parametric rank tests (e.g., Kruskal-Wallis procedures) for comparative analyses of group differences (Gibbons, 1971; Hollander and Wolfe, 1973).

TABLE 1

Perceptions of the expert panel

\begin{tabular}{|c|c|c|c|c|c|c|c|c|c|}
\hline Job & Category & Expert 1 & Expert 2 & Expert 3 & Expert 4 & Expert 5 & Mean & Mode & Std. Dev. \\
\hline 1 & M.L. & 3 & 3 & 2 & 3 & 3 & 2.8 & 3 & 0.45 \\
\hline 1 & U.E. & 1 & 2 & 3 & 2 & 2 & 2.0 & 2 & 0.71 \\
\hline 1 & PST. & 3 & 3 & 2 & 2 & 3 & 2.6 & 3 & 0.55 \\
\hline 1 & MET. & 1 & 2 & 1 & 1 & 2 & 1.4 & 1 & 0.55 \\
\hline 2 & M.L. & 1 & 3 & 1 & 2 & 2 & 1.8 & $1 / 2$ & 0.84 \\
\hline 2 & U.E. & 2 & 3 & 2 & 3 & 2 & 2.4 & 2 & 0.55 \\
\hline 2 & PST. & 1 & 2 & 1 & 2 & 3 & 1.8 & $1 / 2$ & 0.84 \\
\hline 2 & MET. & 1 & 1 & 1 & 2 & 2 & 1.4 & 1 & 0.55 \\
\hline 3 & M.L. & 1 & 1 & 1 & 1 & 1 & 1.0 & 1 & 0.00 \\
\hline 3 & U.E. & 3 & 3 & 3 & 3 & 2 & 2.8 & 2 & 0.45 \\
\hline 3 & PST. & 1 & 2 & 1 & 2 & 1 & 1.4 & 1 & 0.55 \\
\hline 3 & MET. & 1 & 1 & 1 & 1 & 1 & 1.0 & 1 & 0.00 \\
\hline 4 & M.L. & 1 & 3 & 1 & 1 & 1 & 1.4 & 1 & 0.89 \\
\hline 4 & U.E. & 2 & 2 & 2 & 3 & 3 & 2.4 & 2 & 0.55 \\
\hline 4 & PST. & 2 & 2 & 2 & 2 & 3 & 2.2 & 2 & 0.45 \\
\hline 4 & MET. & 1 & 2 & 1 & 2 & 2 & 1.6 & 2 & 0.55 \\
\hline 5 & M.L. & 3 & 3 & 3 & 3 & 3 & 3.0 & 3 & 0.00 \\
\hline 5 & U.E. & 2 & 2 & 3 & 2 & 3 & 2.4 & 2 & 0.55 \\
\hline 5 & PST. & 3 & 3 & 3 & 2 & 3 & 2.8 & 3 & 0.45 \\
\hline 5 & MET. & 2 & 3 & 2 & 1 & 1 & 1.8 & $1 / 2$ & 0.84 \\
\hline 6 & M.L. & 1 & 1 & 1 & 2 & 2 & 1.4 & 1 & 0.55 \\
\hline 6 & U.E. & 2 & 2 & 2 & 2 & 2 & 2.0 & 2 & 0.00 \\
\hline 6 & PST. & 3 & 3 & 1 & 1 & 2 & 2.0 & $1 / 3$ & 1.00 \\
\hline 6 & MET. & 1 & 1 & 1 & 1 & 1 & 1.0 & 1 & 0.00 \\
\hline 7 & M.L. & 1 & 3 & 2 & 3 & 2 & 2.2 & $2 / 3$ & 0.84 \\
\hline 7 & U.E. & 3 & 3 & 3 & 3 & 3 & 3.0 & 3 & 0.00 \\
\hline 7 & PST. & 3 & 2 & 2 & 2 & 3 & 2.4 & 2 & 0.55 \\
\hline 7 & MET. & 1 & 1 & 1 & 1 & 1 & 1.0 & 1 & 0.00 \\
\hline 8 & M.L. & 1 & 1 & 1 & 1 & 1 & 1.0 & 1 & 0.00 \\
\hline 8 & U.E. & 1 & 1 & 1 & 1 & 2 & 1.2 & 1 & 0.45 \\
\hline 8 & PST. & 1 & 2 & 2 & 2 & 2 & 1.8 & 2 & 0.45 \\
\hline 8 & MET. & 1 & 1 & 1 & 1 & 1 & 1.0 & 1 & 0.00 \\
\hline 9 & M.L. & 1 & 1 & 1 & 1 & 1 & 1.0 & 1 & 0.00 \\
\hline 9 & U.E. & 2 & 2 & 2 & 3 & 2 & 2.2 & 2 & 0.45 \\
\hline 9 & PST. & 1 & 2 & 1 & 2 & 2 & 1.6 & 2 & 0.55 \\
\hline 9 & MET. & 1 & 1 & 1 & 1 & 1 & 1.0 & 1 & 0.00 \\
\hline 10 & M.L. & 3 & 3 & 3 & 3 & 3 & 3.0 & 3 & 0.00 \\
\hline 10 & U.E. & 3 & 2 & 3 & 3 & 3 & 2.8 & 3 & 0.45 \\
\hline 10 & PST. & 3 & 3 & 3 & 3 & 2 & 2.8 & 3 & 0.45 \\
\hline 10 & MET. & 3 & 3 & 3 & 2 & 2 & 2.6 & 3 & 0.55 \\
\hline
\end{tabular}

Note: M.L. = manual materials handling activities; U.E. = upper extremity activities; PST. = posture; MET. = metabolic energy expenditure and whole body fatigue. 


\section{RESULTS}

The perceptions of the expert panel (i.e., the "raw data") for the ten study jobs and the associated descriptive statistics are presented in Table 1. The extent of expert consensus, measured using the five-point scoring scheme described above, is presented in Table 2.

\section{Extent of expert consensus}

In general, the experts recorded similar perceptions for a given category of ergonomic stress on a particular job. A single mode (scores of " 3 " or better in Table 2, indicating agreement among at least three of the five experts) was obtained for 87.5 percent $(35 / 40)$ of the expert ratings. "Perfect agreement" (scores of " 5 " in Table 2) was obtained for 30 percent $(12 / 40)$ of the expert ratings and "strong agreement" (scores of " 4 " in Table 2) was obtained for 27.5 percent $(11 / 40)$ of the expert ratings. "Very poor agreement" was obtained for only 2.5 percent $(1 / 40)$ of the ratings. (This occurred on Job 6, where two experts rated postural stress as "insignificant", one expert rated it as "moderate", and two experts rated it as "high". See Table 1. Also, refer to the Discussion section for additional comments on this result.)

The extent of expert consensus was similar for

\section{TABLE 2}

Rating of expert concensus based on a five point scale

\begin{tabular}{lllll}
\hline $\begin{array}{l}\text { Job } \\
\text { number }\end{array}$ & $\begin{array}{l}\text { Manual } \\
\text { lifting }\end{array}$ & $\begin{array}{l}\text { Upper } \\
\text { extremities }\end{array}$ & Posture & Metabolic \\
\hline 1 & 4 & 3 & 4 & 3 \\
2 & 2 & 3 & 2 & 3 \\
3 & 5 & 4 & 3 & 5 \\
4 & 4 & 3 & 4 & 3 \\
5 & 5 & 3 & 4 & 2 \\
6 & 3 & 5 & 1 & 5 \\
7 & 2 & 5 & 3 & 5 \\
8 & 5 & 4 & 4 & 5 \\
9 & 5 & 4 & 3 & 5 \\
10 & 5 & 4 & 4 & 3 \\
Mean & 4.0 & 3.8 & 3.2 & 3.9 \\
\hline
\end{tabular}

Scale: 5-Perfect agreement (five at mode)

4-Very strong agreement (four at mode)

3-Consensus (three at mode)

2-Poor agreement (two modes-contiguous)

1 -Very poor agreement (two modes-not contiguous) the "manual handling", "upper extremities", and "energy expenditure" categories. As shown in Table 2 , the average consensus scores ranged between 3.8 and 4.0 for these categories. Consensus was slightly lower for the "posture" category with an average score of 3.2 for the ten study jobs. It is noteworthy that the experts failed to achieve "perfect agreement" in their perceptions of postural stress on any of the ten jobs.

Kruskal-Wallis procedures (a non-parametric analogy to one-way analysis of variance) were used to evaluate differences in the consensus scores across the four stress categories. These differences were not found to be statistically significant (Kruskal-Wallis " $H$ " $=3.10, p>0.35$ ), indicating a similar level of expert agreement in the four stress categories.

\section{Categorical specificity of results}

While the rating system used in this study was not intended to determine specific causes of ergonomic stress, it was able to establish differences in perceived hazard levels among the four categories of ergonomic stress within a given job. Most of the jobs were found to have widely-varying stress levels for the different categories of interest. For example, Table 1 shows that the manual handling, posture, and energy expenditure stresses on Job 3 were rated "insignificant", while the upper extremity stresses were rated "high". This finding suggests that follow-up analyses should be directed toward measuring and controlling exposures to work activities which stress the upper extremities. (Note: Job 3 required highly repetitive use of a pneumatic tool to fasten nuts while standing at a work bench. This action required a deviated wrist to hold the tool and exposed the operator to vibration. See Appendix B for additional information on job requirements.)

Only one job had the same rating for all four categories. Stresses on Job 10 were rated "high" in each category. This job involved highly repetitive one-handed lifting (approximately 11 times per minute) of $8.3 \mathrm{~kg}$ parts during a depalletizing operation. The job required the operator to repeatedly bend and twist the trunk when retrieving low parts. (See Appendix B for additional details.) These results suggest that detailed follow-up analyses be performed for all four stress categories. 
TABLE 3

Mean scores of perceived stress ( 5 experts $\times 4$ stress categories)

\begin{tabular}{lllllll}
\hline Expert & Manual lifting & Upper extremities & Posture & Metabolic & " $H$ " & $\begin{array}{c}\text { Significance } \\
\text { level }\end{array}$ \\
\hline 1 & 1.6 & 2.1 & 2.1 & 1.3 & 5.38 & n.s. \\
2 & 2.2 & 2.2 & 2.4 & 1.6 & 4.54 & n.s. \\
3 & 1.6 & 2.4 & 1.8 & 1.3 & 8.47 & $p<0.05$ \\
4 & 2.0 & 2.6 & 2.1 & 1.3 & 10.49 & $p<0.025$ \\
5 & 1.9 & 2.4 & 2.4 & 1.4 & 10.17 & $p<0.025$ \\
" $H$ " & 2.58 & 2.13 & 4.28 & 1.07 & & \\
\hline Significance level & n.s. & n.s. & n.s. & n.s. & & \\
\hline
\end{tabular}

Table 3 presents the mean of each expert's perceptions of the ten jobs for each category of ergonomic stress. Kruskal-Wallis procedures were used to test for differences in the perceived stress levels across the four stress categories (See Table for " $H$ " values and corresponding significance levels.) Statistically significant differences ( $p<$ 0.05 ) were found for three of the five experts and for the pooled data of all experts. In each case, the metabolic category received the lowest stress ratings. This result may be interpreted in one of two ways: (1) the expert panel was relatively insensitive to metabolic stresses and therefore gave lower ratings in this category, or (2) the ten jobs selected for this study were inherently lower in energy expenditure demands relative to the other stress categories. A review of the job descriptions presented in Appendix B supports the second interpretation. Most of the jobs were performed by standing operators and required only minimal amounts of walking, stooping, or repetitive lifting.

\section{Inter-expert differences}

Table 3 also presents the results of KruskalWallis analyses to test for differences in perceived stress levels among the members of the expert panel. These analyses were performed for each stress category and for pooled data across all four categories. Differences among the experts were not found to be significant.

\section{Within-expert consistency}

Expert 1 rated the ten study jobs on two occasions, separated by an interval of 11 days. The resulting scores are presented in Table 4 , broken down by job and stress category. Identical ratings were recorded during the two site visits for 82.5 $(33 / 40)$ percent of the paired scores. The energy expenditure category had identical ratings for 90 percent $(9 / 10)$ of the jobs. All other categories had identical ratings for 80 percent $(8 / 10)$ of the jobs. In all cases where non-identical ratings were recorded, differences were limited to adjacent categories of the ordinal scoring system.

\section{Comparison of experts' ratings to the NIOSH WPG}

Table 5 presents a comparison of the experts' ratings to the results of analyses performed using the NIOSH Work Practices Guide (NIOSH, 1981). NIOSH WPG procedures were used to compute the "Acceptable Lift" and "Maximum Permissible Lift" for eight of the ten jobs. The actual weight lifted on each job was compared to these criteria in order to classify the job as "Acceptable", "Administrative Controls Required", or "Hazardous". (The NIOSH method could not be used for Jobs 8 and 9 because these were seated operations which required no lifting. Because lifting stresses were non-existent, these jobs were assumed to be "Acceptable" under the NIOSH rating system.)

The mode of the experts' ratings was 1 (insignificant stress) for five of the jobs rated "Acceptable" using the NIOSH method (Jobs 3, 4, 6, 8, and $9)$. The experts had a split mode of $2 / 3(\bmod -$ erate-high stress) on Job 7 which was also found to be "Acceptable" using the NIOSH method. The experts' mode was 3 (high stress) on two jobs (1 and 5) and 1/2 (low-moderate stress) on one 
TABLE 4

Ratings of one expert on two occasions

\begin{tabular}{|c|c|c|c|c|c|c|c|c|}
\hline \multirow{2}{*}{$\begin{array}{l}\text { Job } \\
\text { number }\end{array}$} & \multicolumn{2}{|c|}{ Manual lifting } & \multicolumn{2}{|c|}{ Upper extremities } & \multicolumn{2}{|c|}{ Posture } & \multicolumn{2}{|c|}{ Metabolic } \\
\hline & Obs. 1 & Obs. 2 & Obs. 1 & Obs. 2 & Obs. 1 & Obs. 2 & Obs. 1 & Obs. 2 \\
\hline 1 & 2 & 3 & 1 & 1 & 2 & 3 & 1 & 1 \\
\hline 2 & 1 & 1 & 2 & 2 & 1 & 1 & 1 & 1 \\
\hline 3 & 1 & 1 & 2 & 3 & 1 & 1 & 1 & 1 \\
\hline 4 & 1 & 1 & 2 & 2 & 1 & 2 & 1 & 1 \\
\hline 5 & 3 & 3 & 3 & 2 & 3 & 3 & 2 & 2 \\
\hline 6 & 1 & 1 & 2 & 2 & 3 & 3 & 1 & 1 \\
\hline 7 & 1 & 1 & 3 & 3 & 3 & 3 & 1 & 1 \\
\hline 8 & 1 & 1 & 1 & 1 & 1 & 1 & 1 & 1 \\
\hline 9 & 1 & 1 & 2 & 2 & 1 & 1 & 1 & 1 \\
\hline 10 & 2 & 3 & 3 & 3 & 3 & 3 & 2 & 3 \\
\hline
\end{tabular}

job (2) rated "Administrative Controls Required" using the NIOSH method. The mode of the experts' ratings was 3 (high stress) on the only job rated "Hazardous" by the NIOSH method (Job $10)$.

A direct comparison between the expert and NIOSH ratings was not feasible due to obvious differences in the definitions of the hazard categories used by the two systems. With this in mind, the information in Table 5 must be interpreted with extreme caution. If caution were relaxed and the two systems were assumed to be equivalent, one might conclude that similar results were obtained for six of the ten jobs. On three of the jobs, however, the experts found a higher hazard level than the WPG while they found a lower hazard level on only one job.

\section{DISCUSSION}

Ergonomic experts are frequently called upon to render opinions concerning the hazard level resulting from specific types of ergonomic stresses on a job. This study was performed to determine how well a panel of five experts agreed among themselves when asked to assign jobs to one of three hazard categories (insignificant, moderate, or high) based on their perceptions of stresses associated with materials handling, upper extremity, posture, and energy expenditure. As presented in Tables 1-3 and discussed previously, the level of agreement among the experts was found to be high.

In order to better understand how the experts developed their ratings, they were encouraged to

TABLE 5

Comparison of experts' perceptions and NIOSH ratings

\begin{tabular}{|c|c|c|c|c|c|c|}
\hline \multirow[t]{2}{*}{ Job } & \multirow{2}{*}{$\begin{array}{l}\text { Actual weight } \\
\text { (kg) }\end{array}$} & \multicolumn{2}{|c|}{ NIOSH criteria } & \multirow[t]{2}{*}{ NIOSH rating } & \multicolumn{2}{|c|}{ Expert score } \\
\hline & & $\overline{\mathrm{AL}}$ & $\overline{\mathrm{MPL}}$ & & $\overline{\text { Mean }}$ & Mode \\
\hline 1 & 20 & 15.1 & 45.2 & Admin. Contr. & 2.8 & 3 \\
\hline 2 & 20 & 19.5 & 58.5 & Admin. Contr. & 1.8 & $1 / 2$ \\
\hline 3 & 3.4 & 21.5 & 64.5 & Acceptable & 1.0 & 1 \\
\hline 4 & 10 & 18.7 & 56.1 & Acceptable & 1.4 & 1 \\
\hline 5 & 21.3 & 19.9 & 59.7 & Admin. Contr. & 3.0 & 3 \\
\hline 6 & 5 & 30.6 & 91.7 & Acceptable & 1.4 & 1 \\
\hline 7 & 15 & 27.8 & 83.3 & Acceptable & 2.2 & $2 / 3$ \\
\hline 8 & a & a & a & Acceptable & 1.0 & 1 \\
\hline 9 & a & a & a & Acceptable & 1.0 & 1 \\
\hline 10 & 8.3 & 1.5 & 4.5 & Hazardous & 3.0 & 3 \\
\hline
\end{tabular}

\footnotetext{
"No lifting was required on this job, NIOSH rating assumed to be "Acceptable".
} 
provide written comments and explanations with their scores. These comments provided insight to the experts' reasoning, and were particularly interesting for the infrequent cases where weak consensus was obtained, such as for the posture ratings on Job 6.

Job 6 was a warehouse packing operation where a standing operator hand-fed parts into a wrapping machine that sealed the part between sheets of paper and clear plastic. Operation of the wrapping machine was controlled by a foot pedal. The parts were lightweight (less than $0.5 \mathrm{~kg}$ each), flexible cables approximately $0.7 \mathrm{~m}$ in length. Unwrapped parts were supplied in a large shipping bin located on the floor, adjacent to the wrapping machine. Periodically (approximately 10 times per hour), the operator would obtain a handful of parts from the bin and carry them to the wrapping machine for sealing. Following the sealing process, parts were carried to a second bin for temporary storage and shipping.

While observing this job for postural stresses, the expert panel recorded the following ratings and comments:

Expert 1. Rating $=3$ due to extreme trunk flexion when obtaining parts from floor level (i.e., the bottom) of supply bin (not observed during site visit). Otherwise, rating $=2$, including some minor trunk bending to obtain parts when working from a full or nearly-full supply bin. Operation of foot pedal requires standing on the left foot while activating the pedal with the right foot.

Expert 2. Rating $=3$. Some amount of trunk twisting and bending when obtaining parts from supply bin and placing finished parts in shipping bin. Constant use of foot pedal and constant standing during operation of wrapping machine.

Expert 3. Rating $=1+$. Operator uses foot pedal when standing.

Expert 4. Rating $=1$. The only bad posture occurs when getting parts from bottom levels of supply bin.

Expert 5. Rating $=2$. Foot pedal requires somewhat awkward foot placement.
Based on these comments, the discrepancy among the experts appears to have resulted from different perception of the awkward trunk postures (flexion and twisting) required to obtain parts from the supply bin. Extremely awkward postures (i.e., severe flexion) only occurred when parts were lifted from the bottom of the bin (reaching down to a height of about $20 \mathrm{~cm}$ above the floor in the "worst" case). Although this irregular activity was not observed during the site visit, the posture required to perform this task was explicitly recognized by Experts 1, 2, and 4. Experts 1 and 2 perceived that this activity created a "high" posture hazard, while expert 4 rated the hazard as "negligible". The scattering of expert opinion may have been caused by the irregular occurrence and/or non-observation of this extreme posture. (Note that Expert 1 would have rated the hazard level as "moderate" if the retrieval of parts from the bottom of the bin was eliminated from this job.)

It is also interesting to note that while posture of the lower extremities was not mentioned in the instructions given to the experts, all panel members made written comments describing awkward postures of the legs and feet while operating the foot pedal on the wrapping machine. Expert 5 may have used this observation to establish a "moderate" hazard rating for postural stress on this job. This result may indicate that the panel members were truly functioning as experts, that is utilizing their broad experience in ergonomics to establish their perceptions of hazard, instead of explicitly following instructions.

The experts also failed to reach a consensus when rating energy expenditure stresses on jobs that utilized worker rotation. For example, Job 5 was performed by two operators who had informally agreed to a " 30 minutes on -30 minutes off" rotation scheme. During the heavy work phase of this cycle, the operator was required to manually carry heavy parts $(21.3 \mathrm{~kg})$ from a table to a shipping rack. This operation was performed at an average frequency of 2.5 parts $/ \mathrm{min}$. Short-term frequencies could be somewhat higher or lower, however, due to variability of the production rate. When assessing this job for energy expenditure stresses, the following comments were recorded by the expert panel: 
Expert 1. Rating $=2$ at peak work time; could be reduced to 1 with rest phase included.

Expert 2. Rating $=3$ during the 30 minutes on, carrying of heavy parts required.

Expert 3. Rating $=1+$ or $2-$ ?

Expert 4. Rating $=1$ based on rotation; 2 with no rotation. Not a lot of steps; therefore whole body expenditure probably less than $3.5 \mathrm{kcal} / \mathrm{min}$. Stresses concentrated on upper extremity, therefore the job is fatiguing.

Expert 5. Rating $=1$ today due to mechanical problems; 3 under normal work pace without rotation; 2 under normal work pace with rotation.

Based on these comments, it is apparent that the experts were unwilling to commit to a single rating for energy expenditure stresses on this job due to the moderating effects of the existing, but informal, job rotation scheme. Instead, a majority of the panel members recorded at least two ratings, usually with qualifying comments. (Note: The results presented previously in Table 1 gave only the first rating of each expert when multiple ratings were presented in the comments.)

The situation discussed above is not unusual. Ergonomists are frequently asked to evaluate stresses on jobs where the observed work method may be considerably different from the documented work method. When this occurs, it is prudent to issue multiple, qualified ratings which demonstrate how changes in work practices can affect the intensity of ergonomic stresses on the operator.

All of the experts reported problems in using a strict three level rating system for those jobs where the observed stresses did not fall cleanly into the "negligible". "moderate", or "high" hazard categories. In these borderline cases, the experts elected to qualify their recorded scores with a plus $("+")$ or a minus ("- "). (These qualifiers were dropped when performing the analyses and preparing the tables presented in the Results section in order to conform with the experimental protocol.) Several members of the panel expressed a preference for using a continuous rating scale; other members accepted the concept of a discrete scale, but felt limited by the small number of categories.

\section{CONCLUSIONS AND RECOMMENDA- TIONS}

This study finds that experts can achieve strong consensus when rating the hazard level of four categories of ergonomic stresses. Expert consensus is less than perfect, however, particularly in situations where job requirements are not constant over the duration of a work shift. Additional studies are needed to develop a better understanding of how experts integrate time-varying work activities when assessing ergonomic stresses. Additional studies are also needed to compare expert ratings to objective measures of ergonomic stress. The comparison, presented above, between expert ratings of $\mathrm{MMH}$ activities and results obtained using the NIOSH WPG, is limited and imprecise due to inherent differences between the two systems. Before additional comparative studies are feasible, however, considerable work must be performed toward the development of consensus procedures to analyze and rate jobs for all types of ergonomic stress.

Furthermore, it should be recognized that expert ratings are only the first step in eliminating ergonomic stressors. In situations where the hazard level is perceived as "moderate" or "high", follow-up analyses must be performed to identify and quantify specific causes of stress. Examples of available analytical tools for performing these follow-up analyses are presented below.

Manual Materials Handling (1) Tables of acceptable lift, push, pull, and carrying forces for MMH tasks (Snook, 1978); (2) Biomechanical models to predict localized stress levels on musculoskeletal tissue (Chaffin and Andersson, 1984); and (3) Equations, nomographs, and slide rules based on the recommendations of the NIOSH Work Practices Guide for Manual Lifting (1981).

Upper extremity stresses. (1) Video and electromyographic documentation of upper extremity postures and forces (Armstrong. 1986a): (2) Task and motion analyses methods to record the force. frequency, and posture associated with upper ex- 
tremity exertions (Armstrong, 1986b); and (3) Checklists to document upper extremity stresses (Joseph, 1986).

Posture. (1) Sample-based posture recording techniques such as the Ovako Work Posture Analysis System (Karhu et al., 1977) and Posture Targeting (Corlett et al., 1979); and (2) Continuous posture recording techniques such as Real Time Posture Analysis (Keyserling, 1986).

Energy Expenditure. (1) Indirect calorimetry based on measurements of oxygen uptake and other correlated variables (Astrand and Rodahl, 1986); (2) Predictions based on description and measurements of task variables (Garg et al., 1978).

Although all of these techniques are time consuming, they are an essential supplement to expert opinion in the identification and resolution of ergonomic problems.

\section{ACKNOWLEDGEMENT AND DISCLAIMER}

This project was funded by joint funds from the UAW/GM National Joint Committee on Health and Safety, which does not necessarily support or endorse the findings herein and which are solely the responsibility of the authors.

\section{REFERENCES}

Abascus Concepts, Inc., 1986. Statview 512+ (Statistical Software). Documentation by Brain Power, Inc. Calabasas, CA.

Apostolakis, G. and Mosleh, A., 1979. Expert opinion and statistical evidence: An application to reactor core melt frequency. Nucl. Sci. Eng., 70: 135-149.

Armstrong, T.J., Chaffin, D.B., Faulkner, J., Herrin, G.D. and Smith, R.G., 1980. Static work elements and selected circulatory responses. Amer. Ind. Hyg. Assoc. J., 41: 254-260.

Armstrong, T.J., 1986a. Biomechanical aspects of upper extremity performance and disorders. The University of Michigan Center for Ergonomics, Ann Arbor, MI.

Armstrong, T.J., 1986b. Upper-extremity posture: Definition, measurement, and control. In: N. Corlett, J. Wilson and I. Manenica (Eds.), The Ergonomics of Working Postures. Taylor and Francis Ltd., London, pp. 59-73.

Astrand, P.O. and Rodahl, K., 1986. Textbook of Work Physiology. McGraw-Hill, New York.

Chaffin, D.B., 1972. A research report on the effects of physical exertion with some design recommendations for jobs requiring physical effort. Department of Industrial and Operations Engineering. The University of Michigan, Ann Arbor, MI.
Chaffin, D.B. and Andersson, G.B.J., 1984. Occupational Biomechanics. Wiley, New York.

Corlett, E.N., Madeley, S.J. and Manenica, I., 1979. Posture targetting: A technique for recording working postures. Ergonomics, 22: 357-366.

Durnin, J.V.G.A. and Passmore, R., 1967. Energy, Work and Leisure. Heineman Educational Books, London.

Garg, A., Chaffin, D.B. and Herrin, G.D., 1978. Prediction of metabolic rates for manual materials handling jobs. Amer Ind. Hyg. Assoc. J., 39: 661-674.

Gibbons, J.D., 1971. Nonparameteric Statistical Inference McGraw-Hill, New York.

Hagberg, M., 1982. Local shoulder muscular strain-Symptoms and disorders. J. Hum. Ergol., 11: 99-108.

Hofer, E., Javeri, V., Loffler, H. and Struwe, D.F., 1985. A survey of expert opinion and its probabilistic evaluation for specific aspects of the SNR-300 risk study. Nucl. Technol., 68(2): $180-225$.

Hollander, M. and Wolfe, D.A., 1973. Nonparametric Statistical Methods. Wiley, New York.

Joseph, B.S., 1986. A participative ergonomic control program in a U.S. automotive plant: Evaluations and implications. $\mathrm{Ph} . \mathrm{D}$. Dissertation, The University of Michigan Center for Ergonomics, Ann Arbor, MI.

Karhu, O., Kansi, P. and Kuorinka, I., 1977. Correcting working postures in industry: A practical method for analysis Appl. Ergon., 8: 199-201.

Kelsey, J.L., Pastides, H. and Bisbee, G.E., 1978. Musculoskeletal Disorders. Prodist, New York.

Keyserling, W.M., 1986. Postural analysis of the trunk and shoulders in simulated real time. Ergonomics, 29: 569-583.

Linstone. H.A. and Turhoff, M., 1975. The Delphi Method. Techniques and Applications. Addison-Wesley, Reading. MA.

National Institute for Occupational Safety and Health, 1981. A Work Practices Guide for Manual Lifting. Technical Report Number 81-122. U.S. Department of Health and Human Services (NIOSH), Cincinnati, OH.

Punnett, L., Fine, L.J., Keyserling. W.M., Herrin, G.D. and Chaffin, D.B., 1987. A case-referent study of back disorders in automobile assembly workers: The health effects of non-neutral postures. The University of Michigan Center for Ergonomics, Ann Arbor, MI.

Silverstein, B., 1985. The prevalence of upper extremity cumulative trauma disorders in industry. Ph.D. Dissertation, Department of Epidemiology, The University of Michigan, Ann Arbor, MI.

Snook, S.H., 1978. The design of manual handling tasks. Ergonomics, 21: 963-985.

\section{APPENDIX A}

\section{DESCRIPTION OF THE EXPERT PANEL}

\section{Expert 1}

Occupation: University Professor, Department of Industrial Engineering. 
Highest degree: Ph.D. (Industrial Engineering and Industrial Health).

Relevant experience: Eight years as a university faculty member performing research, teaching, and consulting in the areas of ergonomics and work measurement.

Principal research areas: Posture analysis, work station design, prevention of occupational musculoskeletal disorders.

\section{Expert 2}

Occupation: University Professor, Department of Industrial Engineering.

Highest degree: M.S.E. (Industrial Engineering)

Relevant experience: 14 years as a university faculty member performing research, teaching, and consulting in ergonomics.

Principal research areas: Posture and force analysis, work station design.

\section{Expert 3}

Occupation: Research Scientist, Department of Occupational Health.

Highest degree: Ph.D. (Epidemiology and Occupational Health).

Relevant experience: Five years of evaluating upper extremity risk factors and health effects in epidemiologic studies.

Principal research areas: Epidemiology of upper extremity cumulative trauma disorders.

\section{Expert 4}

Occupation: University Professor, Department of Occupational Health.

Highest degree: Ph.D. (Occupational Health and Industrial Engineering).

Relevant experience: One year as university professor and eight years as research assistant performing research in the areas of occupational health and ergonomics.

Principal research areas: Management approaches to controlling upper extremity cumulative trauma disorders, work station design.

\section{Expert 5}

Occupation: University Professor, Department of Occupational Health.
Highest degrees: M.D., Dr.P.H. (Occupational Medicine).

Relevant experience: Eleven years as a university faculty member performing research, teaching, and consulting in ergonomics and the epidemiology of musculoskeletal disorders of the upper extremities and lower back.

Principal research areas: Etiology of work-related disorders of the neck, upper limb, and lower back; epidemiology of occupational neurotoxic exposures.

\section{APPENDIX B}

\section{DESCRIPTION OF STUDY JOBS}

Job 1 is a manual materials handling job which requires the worker to transfer steel beams from shipping racks to gravity feed conveyors. Each beam is $132.1 \mathrm{~cm}$ in length, $25.4 \mathrm{~cm}$ in width, 7.6 $\mathrm{cm}$ in depth, and weighs $20.0 \mathrm{~kg}$. Each shipping rack contains 36 beams (stacked six high and six wide) separated with dunnage. Hand heights at lift origin range from $18.5 \mathrm{~cm}$ above floor level to $138.2 \mathrm{~cm}$. This requires the worker to stoop at the lowest level and to lift above shoulder height at the highest level. The worker tends three gravity feed conveyors, each located $1.2 \mathrm{~m}$ from its respective shipping rack (i.e., the distance which the worker must carry each beam). The height of the gravity feed conveyor is $145.7 \mathrm{~cm}$ above floor level. The worker is paced by production welders at the opposite end of the gravity feed conveyors. 933 beams are moved per eight hour shift.

Results of NIOSH WPG Analysis: Acceptable Lift $(\mathrm{AL})=15.1 \mathrm{~kg}$; Maximum Permissible Lift $(\mathrm{MPL})=45.2 \mathrm{~kg} ;$ Rating = Administrative Controls Required.

Job 2 is a welding job which requires the operator to transfer a steel beam (same dimensions as Job 1) to a welding fixture where two metal braces are joined. The cycle begins by removing a beam from a gravity feed conveyor located $1.0 \mathrm{~m}$ behind the operator and $88.1 \mathrm{~cm}$ above floor level. The operator carries the beam to a welding fixture where it is set down at a height of $114 \mathrm{~cm}$. The operator secures the beam down with four handactivated levers. Next, the operator removes the 
two braces from bins (height $=100 \mathrm{~cm}$ ) on each side of the welding fixture. The braces weigh approximately $1.0 \mathrm{~kg}$ each. The operator positions the braces in the welding fixture and secures them by pressing two palm buttons located directly above the fixture (height $=170 \mathrm{~cm}$ ). The operator then grasps a pistol-shaped welding gun and makes two short welds and one long weld to fasten each brace to the beam. The cycle ends with the operator setting the gun down, pressing the palm buttons to eject the beam, and pushing the beam out of the welding fixture. The production standard is 311 beams per eight hour shift.

Results of NIOSH Analysis: $\mathrm{AL}=19.5 \mathrm{~kg}$; $\mathrm{MPL}=58.5 \mathrm{~kg}$; Rating $=$ Administrative Controls Required.

Job 3 is a hand-intensive assembly job which requires a standing operator to drive two nuts onto a steel bracket with a pistol-shaped pneumatic tool. Each bracket is $190.0 \mathrm{~cm}$ in length, $22.0 \mathrm{~cm}$ in width, $12.0 \mathrm{~cm}$ in depth, and weighs 6.8 $\mathrm{kg}$. The brackets are delivered to the operator via a roller conveyor (height $=80 \mathrm{~cm}$ ). The operator stands on the side of the conveyor and begins the cycle by picking two bolts from a container located $84.0 \mathrm{~cm}$ above floor level, and positioning them in an assembly fixture. The operator then grasps one end of the bracket, lifts, and positions it on the fixture so that the bolt threads pass through a pre-punched hole. The fixture is located $91.5 \mathrm{~cm}$ above the floor. The operator next picks two locknuts from a stock container and hand starts them on the bolts. The operator grasps the tool from a hanger $($ height $=83.0 \mathrm{~cm}$ ) and fastens the nuts. The cycle ends with the operator returning the tool to its hanger, removing the bracket from the fixture, and placing it on a conveyor. The production standard is 200 units per hour. Job rotation is used with an operator working for three hours and then rotating to a materials handling job for 1.5 hours.

Results of NIOSH Analysis: $\mathrm{AL}=21.5 \mathrm{~kg}$; $\mathrm{MPL}=64.5 \mathrm{~kg}$; Rating = Acceptable.

Job 4 is an automated welding job which requires the operator to load three pieces of a beam to a welding machine and start an automatic cycle. The cycle begins with the operator removing two $5.0 \mathrm{~kg}$ steel braces from a tray (height $=92.9$ $\mathrm{cm}$ ) located $1.0 \mathrm{~m}$ from the machine. The operator carries these two pieces to the machine and places them in a fixture located $95.0 \mathrm{~cm}$ above floor level. Next, the operator removes a $6.7 \mathrm{~kg}$ steel beam from a table located $1.0 \mathrm{~m}$ on the opposite side of the machine. The operator carries the beam to the machine and places it in a fixture. The cycle ends with operator pressing two palm buttons located at a height of $193.0 \mathrm{~cm}$. This activates the machine and transfers the beam for further processing. The job is self-paced and the operator completes approximately 150 units per hour.

Results of NIOSH Analysis: $\mathrm{AL}=18.7 \mathrm{~kg}$; $\mathrm{MPL}=56.1 \mathrm{~kg}$; Rating = Acceptable.

Job 5 is a manual materials handling job which requires the worker to transfer components from a conveyor to shipping racks. Each component is $160.9 \mathrm{~cm}$ in length, $22.9 \mathrm{~cm}$ in width, $7.6 \mathrm{~cm}$ in depth, and weighs $21.3 \mathrm{~kg}$. The components are delivered to the worker on a belt conveyor located $88.7 \mathrm{~cm}$ above the floor. The worker carries the components $1.5 \mathrm{~m}$ and places them in a shipping rack. Rack storage heights range from $18.5 \mathrm{~cm}$ above floor level to $149.6 \mathrm{~cm}$. This requires the worker to stoop at the lowest level and to lift above shoulder height at the highest level. Two operators are assigned to this job. The operators work on an alternating basis throughout the eight hour shift, rotating after $30 \mathrm{~min}$. The job is selfpaced and the operator transfers approximately 75 units per half-hour.

Results of NIOSH Analysis: $\mathrm{AL}=19.9 \mathrm{~kg}$; $\mathrm{MPL}=59.7 \mathrm{~kg}$; Rating $=$ Administrative Controls Required.

Job 6 is a warehouse packing operation which requires a standing operator to hand feed parts into a wrapping machine which seals the part between sheets of paper and clear plastic. The parts are $70 \mathrm{~cm}$ flexible cable and weigh less than $0.5 \mathrm{~kg}$ each. Cables are delivered to the operator in large shipping bins $(96.7 \mathrm{~cm} \times 96.7 \mathrm{~cm} \times 104.0$ $\mathrm{cm}$ ) located on the floor, adjacent to the wrapping machine. The paper and plastic wrapping materials are provided in the form of rolled stock which is automatically fed to the machine and cut to length during the sealing process. The operator begins the cycle by obtaining a handful of cables from the bin and carrying them to the machine. The operator places the cables on a table beside the wrapping machine and individually feeds them into the machine, which is controlled by a foot pedal. The feed point is located $104.0 \mathrm{~cm}$ above 
floor level. Following the sealing process, parts are hand carried to a second bin for temporary storage and shipping. The job is self-paced and the operator seals approximately 300 cables per hour.

Results of NIOSH Analysis: $\mathrm{AL}=30.6 \mathrm{~kg}$; $\mathrm{MPL}=91.7 \mathrm{~kg}$; Rating $=$ Acceptable .

Job 7 is a warehouse packing operation which requires a standing worker to place parts into a cardboard shipping tube which is then sealed and labelled. The parts are flexible rubber moldings which weigh less than $0.5 \mathrm{~kg}$ each. The worker places two moldings into each tube. The cycle begins with the worker filling an inclined table (height range of $108.8 \mathrm{~cm}$ above floor level to $124.4 \mathrm{~cm}$ ) with 30 lightweight (less than $0.5 \mathrm{~kg}$ ) cardboard tubes. The tubes are obtained from shipping racks $0.5 \mathrm{~m}$ from the table. Lifting heights of the tubes range from $18.5 \mathrm{~cm}$ to $149.6 \mathrm{~cm}$. Next, the worker removes two moldings from cardboard boxes located $1.5 \mathrm{~m}$ from the table. Lifting heights of the moldings range from floor level to $120 \mathrm{~cm}$. The worker inserts the two moldings into the tube. This step is repeated until all 30 tubes are filled. Next, the worker removes 30 cardboard plugs from a box located under the packing table. The worker then pounds (with base of hand) the plugs into the open end of the tubes. Finally, the worker applies a label to each tube and pushes a lever which allows the tubes to roll into a shipping rack. The job is self-paced and the worker packs approximately 72 units per hour.

Results of NIOSH Analysis: $\mathrm{AL}=27.8 \mathrm{~kg}$; $\mathrm{MPL}=83.3 \mathrm{~kg}$; Rating = Acceptable .

Job 8 is a seated fork truck operation in a warehouse. The driver removes loaded pallets from a receiving area and transport them to their designated storage location. The driver remains seated in the fork truck most of the shift, but occasionally must dismount the fork truck to clear obstructions. The job is self-paced.

Since no lifting is required, the NIOSH rating is assumed to be Acceptable.

Job 9 is a packing operation which requires a seated worker to place a variety of small parts (all less than $0.2 \mathrm{~kg}$ ) into pre-made boxes during a semi-automated packing process. The work cycle consists of grasping a part and placing it in a box. The boxes are transported past the worker on a conveyor which is located $66.1 \mathrm{~cm}$ above floor level and $7.0 \mathrm{~cm}$ wide. The parts are supplied to the worker from an inclined tray located $15.2 \mathrm{~cm}$ above the conveyor. The worker packs approximately 1800 parts per hour.

Since no lifting is required, the NIOSH rating is assumed to be Acceptable.

Job $\mathbf{1 0}$ is a materials handling job which requires the operator to transfer a variety of parts from pallets to a belt conveyor. At the time of the experts' visit, disk-shaped objects were being handled. Each disk had a diameter of $30.0 \mathrm{~cm}$ and weighed $8.3 \mathrm{~kg}$. Each pallet contained 180 disks (20 levels with 9 per level). The lowest level of disks was $15.0 \mathrm{~cm}$ above floor level and the highest level was $110.0 \mathrm{~cm}$. This required prolonged stooping when working at the bottom rows of the pallets. The conveyor was located $84.0 \mathrm{~cm}$ above floor level. The worker stood between the conveyor and the pallets which were located $1.0 \mathrm{~m}$ from the conveyor. The job was self-paced and the worker was observed to transfer approximately 15 disks per minute. Informal job rotation was used.

Results of NIOSH Analysis: $\mathrm{AL}=1.5 \mathrm{~kg}$; $\mathrm{MPL}=4.5 \mathrm{~kg}$; Rating $=$ Hazardous . 